\title{
Demand incidence of retinal detachment in Brazil
}

\begin{abstract}
Aim To evaluate the epidemiological characteristics of retinal detachment in a defined urban population in the Southeast of Brazil.

Methods A retrospective study of patients consulted at the Department of Ophthalmology, State University of Campinas, São Paulo, Brazil, with retinal detachment between June 1, 2003 and July 31, 2004. Data were entered into the Statistical Package for the Social Sciences (version 10.0). Results There were a total population of 3389294 in the 42 cities of Campinas catchment area. A total of $\mathbf{3 1 3}$ patients fitted the inclusion criteria. The overall demand incidence of retinal detachment was 9.2:100 000. The number of males peaked in the 50-79 age group, whereas that of the females peaked in the 60 to $80+$ age group. The ages ranged from 4 months to 84 years (mean 49.3 ).

The female-to-male ratio was 1:2.1.

Nontraumatic phakic detachments had the highest demand incidence of 7.1:100 000. The demand incidence of nontraumatic aphakic detachments was very low at 0.09:100 000 .

Almost one third of all patients seeking treatment presented inoperable cases of retinal detachments.

Conclusions This is the first study of demand incidence of retinal detachment in Latin Americans. The age-specific demand incidence increases with age. Nontraumatic phakic detachments were the most common type of detachment. The incidence of the traumatic types of detachment was higher in males than that in females. Such data are important to plan and implement vitreoretinal services taking into account the population likely to be served. Eye (2007) 21, 348-352. doi:10.1038/sj.eye.6702202; published online 6 January 2006
\end{abstract}

Department of

Ophthalmology,

School of Medical Sciences, State University of

Campinas,

São Paulo,

Brazil

Correspondence:

PH Limeira-Soares,

Rua Porto Alegre, 156

N. Sra. das Dores,

Caruaru, Pernambuco,

CEP 55004-270, Brazil

Tel: +55 819609 0556/

+55 8137215510 ;

Fax: +55 1937888680

E-mail: limeira@

fcm.unicamp.br

Received: 22 June 2005 Accepted in revised form: 18 October 2005;

Published online: 6 January 2006

There are no competing interests to declare
Keywords: retinal detachment; epidemiology; health services needs and demand; health service area
PH Limeira-Soares, RPC Lira, CEL Arieta, N Kara-José

\section{Introduction}

The ophthalmic needs of the Brazilian population have not been well studied. Analysis of demand patterns for vitreoretinal services can be used as one of the objective measures when planning ophthalmic services requirements and provision of resources. ${ }^{1}$ In recent years, there has been significant demand for ophthalmic services and the resulting appointment delays cause unacceptable burden to society. ${ }^{1-3}$

Despite the fact that retinal detachment (RD) is an important sight threatening condition, there are no national statistics either quantifying or analysing this disorder. In order to plan services, numbers are derived from estimates of the World Health Organization in developing countries which do not necessarily apply to Brazil. $^{4}$

In the 2000 Census, some questions were asked to obtain information on visual impairment in the population, in accordance with a Federal Law enacted in 1993. According to this Census 159824 people considered themselves unable to see. This source is a starting point in the evaluation of the nation's ophthalmic health. ${ }^{5}$ However, the main criticisms are that it does not discriminate specific ophthalmic conditions nor determine the workload they represent for medical services.

Population-based studies that could yield results with reasonable precision are very expensive to conduct, so alternative ways to assess the magnitude of the problem have been used. ${ }^{5}$ This paper examines the demand incidence of retinal detachment in a defined urban population in the Southeast of Brazil.

\section{Materials and methods}

This is a retrospective study of patients consulted at the Department of Ophthalmology, State University of Campinas, São Paulo, Brazil, with RD between June 1, 2003 and July 31, 2004. 
The Department of Ophthalmology is the only center for vitreoretinal repair for the public health district of Campinas, with 42 surrounding cities (2003 total population $=3389294$ ). São Paulo city is not included. The Department of Ophthalmology provides publicaly funded treatment for patients with retinal detachments referred by the health services of the catchment area (Figure 1). Population data for the Campinas catchment area were based on the findings of the 2003 Brazilian Census estimates. ${ }^{4}$

For this report data were obtained by searching the computerized databases of the Department of Ophthalmology. The medical record linkage system has been recently enhanced to cover all the patients consulted and facilitates studies of disease occurrence and treatment. The study has obtained the approval from the State University of Campinas Research Ethical Committee.

Data extracted from the medical records and collected on a 4-page form included, hospital record number, age, sex, place of residence, and whether or not this was the first eye appointment at the Department. The research form was tested and modified to ensure that it was comprehensible. The medical records of all identified patients were reviewed and filled out by one ophthalmologist investigator (PHLS) to ensure the accuracy of coded data.

The inclusion criteria were: patients domiciled in the catchment area cities of the Department of Ophthalmology, State University of Campinas consulted in the study period; patients with primary RD of the rhegmatogenous type, including phakic, aphakic and pseudophakic traumatic and nontraumatic cases; and patients with RD after intraocular surgery. The exclusion criteria were retinoschisis, retinal cysts, serous RD, patients with retinopathy of prematurity (ROP) that has progressed to retinal detachment, other tractional retinal detachments, and patients who redetached post RD surgery.

The demand incidence was calculated by dividing the number of new cases of RD presenting to the eye department and diagnosed by the trained staff as obtained in this study, by the population estimates in the catchment area for $2003 .{ }^{4}$ One new case is a new RD

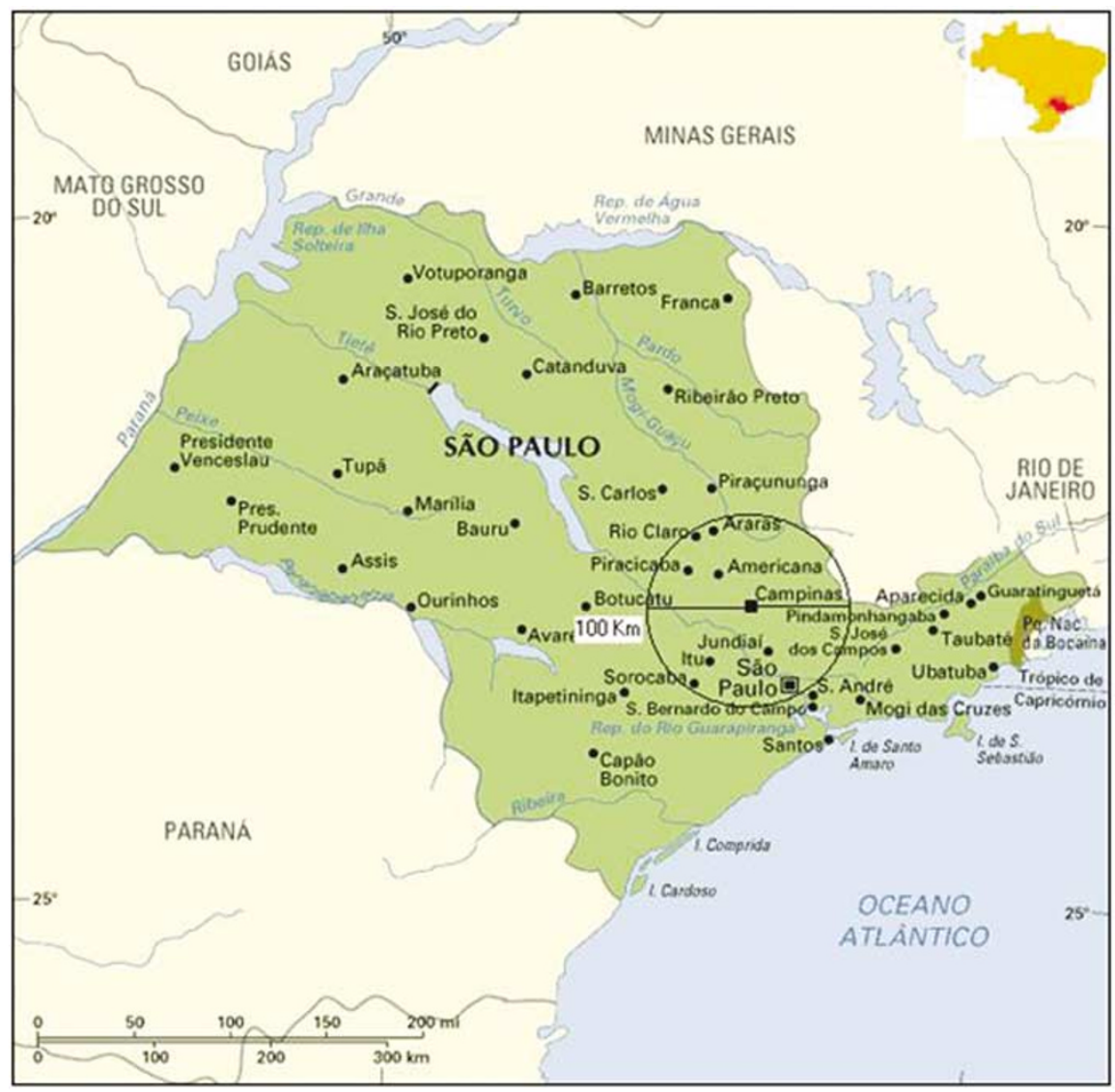

Figure 1 Map of São Paulo State with the encircled catchment area of the Department of Ophthamology. São Paulo city is not included in the Campinas catchment area. Upper right shows schematic map of Brazil, with São Paulo State highlighted. (Available: www.ibge.gov.br/cidades @-accessed November 1, 2004). 
either in one or both eyes at the time of the appointment. The age-specific demand incidence was calculated by dividing the number of cases by the number of people in the population for the specific age group per 100000 in the Campinas catchment area.

The International Statistical Classification of Diseases, 10th revision ${ }^{6}$ ICD-10 diagnoses code H33.0 was used to identify the retinal detachment-related diagnoses made on the consecutive admissions of catchment area residents to the Department of Ophthalmology.

The data were entered into the Statistical Package for the Social Sciences (version 10.0).

\section{Results}

There were 1778 new consultations in the Department of Ophthalmology for vitreoretinal disorders during the study period. Further analysis showed that 397 new patients seen in the Department had RD of all types. In all, 313 patients fitted the inclusion criteria for the study. For the entire study population, the overall demand incidence of RD was 9.2:100 000 in the Campinas catchment area per 100000 population per year.

The total population and the number of patients with retinal detachment consulted during the study period are shown in Table 1.

Table 2 reveals the demand incidence rates by age range and gender. The number of males peaked in the 50-79 age group, whereas that of the females peaked in the 60-80+ age group.

As indicated in Table 3, there were no traumatic cases of pseudophakic detachments within the Campinas catchment area during the study period. Nontraumatic phakic detachments had the highest demand incidence of 7.1:100 000, whereas the demand incidence of nontraumatic aphakic detachments was very low at 0.09:100 000 .

The ages ranged from 4 months to 84 years (mean 49.3). The ages of the females ranged from 4 months to 84 years, whereas the males ranged from 6 months to 83 years (Table 4). The mean age for females was slightly higher than that for males. The female-to-male ratio was 1:2.1.

Of particular concern are the 94 (29.6\%) patients whose retinal detachments were regarded as inoperable. In all, $62.8 \%$ (59) were males whereas $37.2 \%$ (35) were females. These cases included patients presenting either severe visual impairment (light perception or no perception of light) or marked proliferative vitreoretinopathy (grade C types 4 and 5 contraction). ${ }^{7}$

\section{Discussion}

We are unaware of any research that has attempted to comprehensively evaluate the demand incidence of the
Table 1 Campinas catchment area population and number of patients with retinal detachment consulted at the Department of Ophthalmology, between June 1, 2003 and July 31, 2004.

\begin{tabular}{lrrrrc}
\hline Age range & $\begin{array}{c}\text { All } \\
\text { persons }\end{array}$ & Male & Female & $\begin{array}{c}\text { Number of } \\
\text { RD } \\
\text { (males) }\end{array}$ & $\begin{array}{c}\text { Number of } \\
\text { RD } \\
\text { (females) }\end{array}$ \\
\hline $0-9$ & 561811 & 286.379 & 275.432 & 3 & 2 \\
$10-19$ & 638612 & 322.347 & 316.265 & 12 & 3 \\
$20-29$ & 618815 & 310.641 & 308.174 & 22 & 8 \\
$30-39$ & 553477 & 272.951 & 280.526 & 34 & 11 \\
$40-49$ & 443174 & 217.789 & 225.385 & 26 & 14 \\
$50-59$ & 270976 & 133.249 & 137.727 & 44 & 13 \\
$60-69$ & 172291 & 80.696 & 91.595 & 45 & 26 \\
$70-79$ & 95619 & 41.987 & 53.632 & 22 & 14 \\
$80+$ & 34519 & 13260 & 21.259 & 5 & 9 \\
& & & & & \\
Total & 3389294 & 1679299 & 1709995 & 213 & 100 \\
\hline
\end{tabular}

${ }^{\mathrm{a}} \mathrm{RD}=$ retinal detachment

Table 2 Demand incidence according to age range and gender per 100000 population per year

\begin{tabular}{ccrr}
\hline Age range & $\begin{array}{c}\text { Age-specific } \\
\text { demand } \\
\text { incidence }\end{array}$ & Males & Females \\
\hline $0-9$ & $0.9: 100000$ & $1.0: 100000$ & $0.7: 100000$ \\
$10-19$ & $2.4: 100000$ & $3.7: 100000$ & $0.9: 100000$ \\
$20-29$ & $6.6: 100000$ & $7.1: 100000$ & $2.6: 100000$ \\
$30-39$ & $8.7: 100000$ & $12.5: 100000$ & $3.9: 100000$ \\
$40-49$ & $13.3: 100000$ & $11.9: 100000$ & $6.2: 100000$ \\
$50-59$ & $34.0: 100000$ & $33: 100000$ & $9.4: 100000$ \\
$60-69$ & $49.9: 100000$ & $55.8: 100000$ & $28.4: 100000$ \\
$70-79$ & $38.7: 100000$ & $52.4: 100000$ & $26.1: 100000$ \\
$80+$ & $40.6: 100000$ & $23.5: 100000$ & $42.3: 100000$ \\
& & & \\
Total & $9.2: 100000$ & $12.7: 100000$ & $5.8: 100000$ \\
\hline
\end{tabular}

Brazilian population relative to patients with sight threatening conditions such as retinal detachment, who must be referred to a hospital eye department.

The total demand incidence of RD in the Campinas catchment area was 9.2:100 000. These data are not dissimilar from results in Sweden (10.6:100 000), ${ }^{8}$ and Singapore (10.5:100 000). ${ }^{9}$ Our calculations underestimate the actual incidences. The profile of private health plans shows that the Southeast Region concentrates $70 \%$ of those covered people in Brazil. ${ }^{10}$ Campinas constitutes a large urban city and private health plans cover at least $50 \%$ of its population. ${ }^{11}$ Our study relates to patients covered by publicaly funded health services with retinal detachments referred from services of the Campinas catchment area. In this regard, the real picture may be comparable to previous studies with higher incidences. ${ }^{12,13}$ 
Table 3 Demand incidence in the Campinas catchment area for types of retinal detachments

\begin{tabular}{lcc}
\hline Types of RD & Number of $R D$ & Demand incidence \\
\hline Nontraumatic & & \\
$\quad$ Aphakia & 7 & $0.2: 100000$ \\
Pseudophakia & 34 & $1.0: 100000$ \\
Phakia & 242 & $7.1: 100000$ \\
Total & 283 & $8.3: 100000$ \\
& & \\
Traumatic & 3 & $0.09: 100000$ \\
Aphakia & $\mathrm{NIL}$ & NIL \\
Pseudophakia & 27 & $0.8: 100000$ \\
Phakia & 30 & $0.9: 100000$ \\
Total & & \\
& 313 & $9.2: 100000$ \\
Total & & \\
\hline
\end{tabular}

Table 4 Age range and gender in the Campinas catchment area

\begin{tabular}{lcc}
\hline Gender & Age range & Mean (years) \\
\hline Females & 4 months-84 years & 50.8 \\
Males & 6 months-83 years & 48.6 \\
\hline
\end{tabular}

This work and others ${ }^{14}$ have indicated that the demand incidence is very low in the younger populations. The age-related annual incidence of $\mathrm{RD}$ for the population aged 10-19 years in our study was 2.4:100 000, which compares with 2.9:100000 in the Rosner et al study. ${ }^{14}$

The age-specific demand incidence increases with age. ${ }^{15}$ There is a high age-specific demand incidence in the 50-79-year-old male group and in the 60- to $80+$-year-old female group in the Campinas catchment area. This compares with the majority of studies of RD incidence. ${ }^{15,16}$ As stated by Mowatt et $a l^{15}$ the age structure of the local population needs to be taken into account when planning vitreoretinal services.

Nontraumatic phakic detachments were the most common type of RD which compares to other studies. ${ }^{15,17,18}$ In our study, the demand incidence of phakic nontraumatic RD was 7.1:100000, which is comparable to Wolverhampton $(9.7: 100000)^{15}$ and the Kumamoto (9.8:100000) studies. ${ }^{17}$

The demand incidence of nontraumatic aphakic RD has been low in several studies since 1990s. ${ }^{15,17}$ The demand incidence of this type of detachment in our study was 0.2:100000, which was substantiated with the studies of Walsall, ${ }^{15}$ Wolverhampton, ${ }^{15}$ and Kumamoto, ${ }^{17}$ respectively, $0.1,0.3$, and 0.5 per 100000 .

The demand incidence of traumatic RD is very low. Mowatt et $a l^{15}$ reported no occurrence of traumatic aphakic detachments. This contrasts with the demand incidence rates of our study, 0.09:100 000. With respect to gender, the incidence of the traumatic types of detachment was higher in males than that in females, $8.2 \%$ (26) and $1.2 \%$ (4), respectively.

This is the first study of demand incidence of retinal detachment in Latin Americans. Ethnic differences in demand incidence could not be studied since our population cannot be separated into isolated racial groups. Notwithstanding, gross comparison with other reports reveals that our demand incidence rates are not as low as the Black population ${ }^{15,19}$ and Asians ${ }^{15}$ nor as high as the Whites ${ }^{15}$ rates.

Almost one third of all patients seeking treatment presented inoperable cases of retinal detachments. This appears to be a problematic compound of deficiencies in the referral chain with patients of lower socio-economic status who tend to be less-informed. Properly designed future studies are needed to elucidate these problems.

There are several limitations to this study. This is a hospital-based study and it represents a selected sample of the general population. ${ }^{1}$ Demand incidence underestimates the true incidence of the disease, ${ }^{17}$ it is possible that a number of patients with RD seek for private treatment, ${ }^{20}$ and patients from peripheral areas may be referred elsewhere. ${ }^{15}$ However, demand incidence is an important indicator of health need for acute conditions causing sudden sensory loss. ${ }^{21}$

The data presented herein demand attention if the patterns and incidence of retinal detachment are to be understood. Such data are important to plan and implement vitreoretinal services taking into account the population likely to be served. Implicit in our discussion is that the limited resources force priorities in the public health. This prioritizing will require greater information regarding population values and the quantifiable financial costs.

\section{References}

1 Sheldrick JH, Vernon SA, Wilson A, Read SJ. Demand incidence and episode rates of ophthalmic disease in a defined urban population. BMJ 1992; 305: 933-936.

2 Covolo GA. Avaliação da demanda atendida num modelo de atenção secundária em saúde ocular (thesis) (Demands assessment in a secondary eye care service). Campinas: State University of Campinas, São Paulo, 2003.

3 Shaw DE, Gibson JM, Rosenthal AR. A year in a general ophthalmic outpatient department in England. Arch Ophthalmol 1986; 104: 1843-1846.

4 Muñoz B, West SK. Blindness and visual impairment in the Americas and the Caribbean. Br J Ophthalmol 2002; 86(5): 498-504.

5 Fundação Instituto Brasileiro de Geografia e Estatística: Rio de Janeiro. (Brazilian Census and Statistical Foundation). Available from URL: http://www.ibge.gov.br. (accessed November 1, 2004). 
6 World Health Organization. International statistical classification of diseases, injuries and causes of death, 10th revision. Geneva: WHO, 1993.

7 Machemer R, Aaberg TM, Freeman HM, Irvine AR, Lean JS, Michels RM. An updated classification of retinal detachment with proliferative vitreoretinopathy. Am J Ophthalmol 1991; 112(2): 159-165.

8 Törnquist R, Stenkula S, Törnquist P. Retinal detachment: a study of a population-based patient material in Sweden 1971-1981- I. Epidemiology Acta Ophthalmol 1987; 213: 213-222.

9 Wong T, Tielsch JM, Schein OD. Racial difference in the incidence of retinal detachment in Singapore. Arch Ophthalmol 1999; 117: 379-383.

10 Pinto LF, Soranz, DR. Private health plans: populational coverage in Brazil. Ciência \& Saúde Coletiva 2004; 9(1): 85-98.

11 Derengowski MG, Fonseca JF. Private health plans national forum. Agência Nacional de Saúde Suplementar (Private Health Plans Brazilian Agency). Available from URL: http://www.ans.gov.br. (accessed May 1, 2005).

12 Rowe JA, Erie JC, Baratz KH, Hodge DO, Gray DT, Butterfield L et al. Retinal detachment in Olmsted Country, Minnesota, 1976 through 1995. Ophthalmology 1999; 106: 154-159.

13 Algvere PV, Jahnberg P, Textorius O. The Swedish Retinal Detachment Register. 1. A database for epidemiological and clinical studies. Graefes Arch Clin Exp Ophthalmol 1999; 237: 137-144.

14 Rosner M, Treister G, Belkin M. Epidemiology of retinal detachment in childhood and adolescence. J Paediatr Ophthalmol Strabismus 1987; 24: 42-44.

15 Mowatt L, Shun-Shin G, Price N. Ethnic differences in the demand incidence of retinal detachments in two districts in the West Midlands. Eye 2003; 17: 63-70.

16 Haimannn MH, Burton TC, Brown CK. Epidemiology of retinal detachment. Arch Ophthalmol 1982; 100: 289-292.

17 Sasaki K, Ideta H, Yonemoto J, Sumiyoshi T, Hirose A, Oka C. Epidemiology characteristics of rhegmatogenous retinal detachment in Kumamoto. Jpn Graefe's Arch Clin Exp Ophthalmol 1995; 233: 772-776.

18 Wilkes SR, Beard CM, Kurland LT, Robertson DM, ÓFallon WM. The incidence of retinal detachment in Rochester, Minnesota, 1970-1978. Am J Ophthalmol 1982; 94: 670-673.

19 Peters AL. Retinal detachment in black South Africans. S Afr Med J 1995; 3: 158-159.

20 Thompson JR. The demand incidence of cataract in Asian immigrants to Britain and their descendants. Br J Ophthalmol 1989; 73(12): 950-954.

21 Shanks J, McCallum A. Needs and demands for ophthalmology services. BMJ 1992; 305(6867): 1501-1502. 